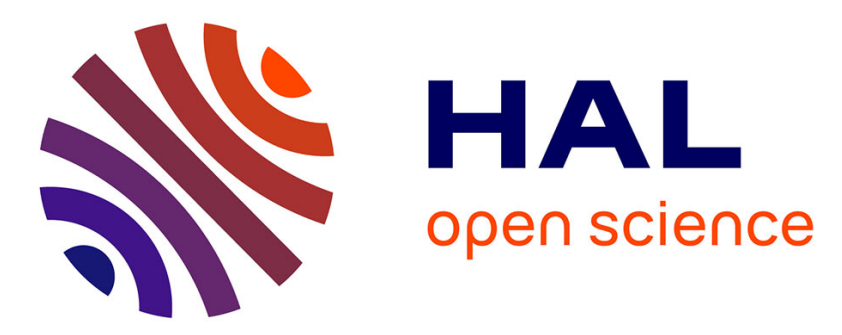

\title{
Axisymmetric formulation for boundary integral equation methods in scalar potential problems
}

Laurent Krähenbühl, Alain Nicolas

\section{To cite this version:}

Laurent Krähenbühl, Alain Nicolas. Axisymmetric formulation for boundary integral equation methods in scalar potential problems. IEEE Transactions on Magnetics, 1983, 19 (6), pp.2364 - 2366. 10.1109/TMAG.1983.1062872 . hal-00414086

\author{
HAL Id: hal-00414086 \\ https://hal.science/hal-00414086
}

Submitted on 8 Sep 2009

HAL is a multi-disciplinary open access archive for the deposit and dissemination of scientific research documents, whether they are published or not. The documents may come from teaching and research institutions in France or abroad, or from public or private research centers.
L'archive ouverte pluridisciplinaire HAL, est destinée au dépôt et à la diffusion de documents scientifiques de niveau recherche, publiés ou non, émanant des établissements d'enseignement et de recherche français ou étrangers, des laboratoires publics ou privés. 
Abstract : Axisymmetric geometries often appaear in electromagnetic device studies. The authors present an original formulation for Boundary. Integral Equation methods in scalar potential problems. This technique requires only $2 \mathrm{D}$ boundary in the $\mathrm{r}-\mathrm{z}$ plane and evaluation of the equations only on those boundaries.

\section{INTRODUCTION}

Scalar potential problems are described by Laplace's equation :

$$
\Delta \psi=0
$$

in the general 3D space.

When the geometry is an axisymmetric there are two possibilities :

- use cylindrical coordinates, express equation (1) in this set of coordinates and note that each quantity is invariant in the azimuthal direction Laplace equation becomes :

$$
\frac{\partial^{2} \varphi}{\partial z^{2}}+\frac{\partial^{2} \varphi}{\partial r^{2}}+\frac{1}{r} \cdot \frac{\partial^{\varphi}}{\partial r}=0
$$

Boundary Integral Equations have to developed with operator :

$$
\frac{\partial^{2}}{\partial z^{2}}+\frac{\partial^{2}}{\partial r^{2}}+\frac{1}{r} \cdot \frac{\partial}{\partial r}
$$

This gives complicated expressions.

- the second method we propose to develop is to express the BIE in 3D space and to integrate all the invariant quantities analytically before solving the equations.

\section{AXISYMMETRIC FORMULATION}

In a 3D space Laplace equation is transformed into BIE equation :

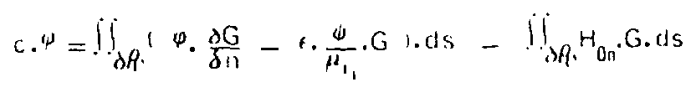

as shown in previous publications $|1|$.

When $\psi, \psi$ and $H_{o n}$ are constant along one part of the boundary $\delta A$, partial integration of functions $G$ and $\delta G / \delta n$ along that direction can be made. As an example it can be shown that partial integration of 3D Green's function

$$
G=\frac{1}{4 \pi r}
$$

over a straight line gives 2D Green's function :

$$
c_{2 D}=-\frac{1}{2 \pi} \cdot \log r
$$

\section{The authors are with}

Dipartement d'Electrotechnique - ERA 908

Ecole Centrale de Lyon - BP 163

US131 ECULLY CEDEX - FRANCE
In axisymetric geometry physical quantities keep constant values on circular lines : Green's function $G$ and derivative function $\partial G / \partial n$ have to be integrated on circles.

By this way a $2 \mathrm{D}$ Boundary Integral Equation can be generated in the $r-z$ plane, similar to those in $x-y$ plane $|4|$.

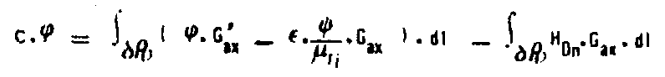

It can be noticed that $G$ gives the potential of a uniform charge distribution on a circle. classical development $|2|$ can be applied to obtain function $G_{a x}$ :

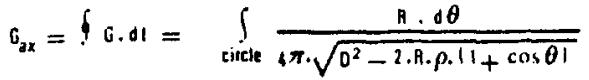

$$
\begin{aligned}
& =\frac{R}{\pi \cdot D} K\left(k^{2}\right)
\end{aligned}
$$

$\mathrm{k}=2 \cdot \sqrt{\mathrm{R} \rho} / \mathrm{D}$

where :

$k$ : complete elliptic integral of the first kind $|3|$

$\rho, \mathrm{R}, \mathrm{D}$ : as shown on Fig. 1 ment :

Function $G^{\prime}{ }_{a x}$ is obtained by a similar develop-

$G_{\mathrm{ax}}^{\prime}=\oint \frac{\partial G}{\partial \mathrm{n}}, \mathrm{d} 1$

$=-\frac{\cos \alpha}{2 \pi D} \cdot K\left(k^{2}\right)+\frac{1}{2 \pi D} \cdot\left[D \cdot[D \cdot \cos \alpha-2 \cdot R \cdot \cos (\alpha-\gamma)] \cdot E\left(k^{2}\right)\right.$

with

$\mathrm{E}:$ complete elliptic integral of the second kind. $\alpha, \gamma, D^{\prime}$ : as shown on Fig. 1
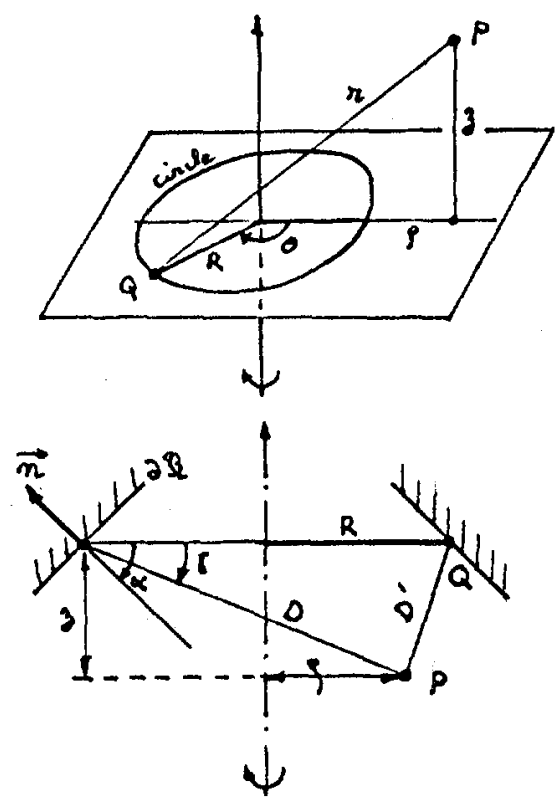

Figure 1 


\section{FLUX DENSITY CALCULATION}

The induced magnetic field in a point $p$ of the region $A_{1}$ :

$$
H_{i}=-\operatorname{grad} \varphi
$$

can be computed directly by integration of $\varphi$ and $\phi$ on the boundary $\delta A$ :

$$
\overrightarrow{\mathrm{H}}_{i}=-\int_{\partial f_{b}}\left[\varphi \cdot g \overrightarrow{\mathrm{rad}} G_{d x}^{\prime}-\left(\epsilon \frac{\psi}{\mu_{r}}+\mathrm{H}_{o n}\right) \cdot g \overrightarrow{\mathrm{rad}} G_{a x}\right] \cdot d 1
$$

with

$$
\begin{aligned}
& \frac{\mathrm{dG}_{\mathrm{ax}}}{\mathrm{d} \rho}=\frac{\mathrm{R}}{\pi \mathrm{D}}\left(-\frac{\mathrm{R}+\rho}{\mathrm{D}^{2}} \cdot \mathrm{K}+\frac{\mathrm{dK}}{\mathrm{dk}} \cdot \frac{\mathrm{dk}}{\mathrm{d} \rho}\right) \\
& \frac{d G_{d x}}{d z}=\frac{R}{\pi D}\left(-\frac{z}{D^{2}} \cdot K+\frac{d K}{d k} \cdot \frac{d k}{d z}\right) \\
& \frac{\mathrm{dG}_{\mathrm{ax}}^{\prime}}{\mathrm{d} \rho}=-\frac{\cos \alpha}{2 \cdot \mathrm{R}} \cdot \frac{\mathrm{d} \mathrm{G}_{\mathrm{ax}}}{\mathrm{d} \rho} \\
& +\frac{D \cdot \cos \alpha-2 \cdot R \cdot \cos (\alpha-\gamma)}{2 \cdot \pi \cdot D^{12}} \cdot\left(\frac{d E}{d k} \frac{d k}{d \rho}+\frac{2 \cdot(R-\rho)}{D^{1 / 2}} \cdot E\right) \\
& +\frac{1}{2 \cdot \pi \cdot D^{12}} \cdot\left[(\rho-R) \cdot \cos \alpha+\frac{2 \cdot R}{D}(R+\rho) \cdot \cos (\alpha-l)\right] \cdot E \\
& \frac{d G_{\mathrm{ax}}^{\prime}}{d \mathrm{z}}=-\frac{\cos \alpha}{2 \cdot \mathrm{R}} \cdot \frac{d G_{\mathrm{ax}}}{\mathrm{dz}} \\
& +\frac{D \cdot \cos \alpha-2 \cdot R \cdot \cos (\alpha-\gamma)}{2 \cdot \pi \cdot D^{12}} \cdot\left(\frac{d E}{d k} \frac{d k}{d z}-\frac{2 \cdot z}{D^{12}} \cdot E\right) \\
& +\frac{1}{2 \cdot \pi \cdot D_{D}^{\prime 2}} \cdot\left[z \cdot \cos \alpha-2 \cdot R\left(\sin \alpha-\frac{z}{D} \cdot \cos \left(\alpha-l^{\prime}\right)\right)\right] \cdot E
\end{aligned}
$$$$
\frac{d K}{d k}=\frac{1}{k} \cdot\left(\frac{E}{1-k^{2}}-K\right)
$$$$
\frac{d E}{d k}=\frac{1}{k} \cdot(E-k)
$$$$
\frac{d k}{d z}=-\frac{z \cdot k^{3}}{4 \cdot k \cdot \rho}
$$$$
\frac{d k}{d \rho}=\frac{k}{2 . \rho}-\frac{k^{3}}{4} \cdot \frac{R+\rho}{R . \rho}
$$$$
K=K\left(k^{2}\right) \quad E=E\left(k^{2}\right)
$$

It must be noticed that these expressions depend on the same functions $K$ and $E$ as $G_{a x}$ and $G^{\prime}{ }^{\prime} x^{\circ}$

When the point $P$ is on the boundary, a more simple expression can be used :

$$
\vec{H}_{i}=-\left(\epsilon \frac{\phi}{\mu_{1}}+h_{o n}\right) \cdot \vec{n}-\frac{\partial \varphi}{\partial t} \cdot \vec{t}
$$

an equivalent result is obtained in this way. However computing time is less important in this case.

\section{NUMERICAL DEVELOPMENT}

Numerical calculation of integrals $K$ and $E$ can be done in several ways :

- numerical integration.

- asymptotic development |3|;

- tabulation and interpolation.
As these integrals have to be computed a large number of times, the third solution appears to be the most convenient.

Function $E$ is always regular, but $K$ becomes singular when $r_{P Q} \rightarrow 0$. This singularity is similar to Log( $r)$ singularity, and Gaussian quadrature formulae with weight function $\log (t)$ are well matched for evaluation of the integral (6) of function $k$.

This development is now applied in PHIAX program, using classical techniques $|1|,|4|$.

NUMERICAL RESULT

The analytical solution is known for a ferroma-

\begin{tabular}{|c|c|c|c|c|c|c|}
\hline \multirow[t]{2}{*}{ Po } & \multicolumn{3}{|c|}{ Potential } & \multicolumn{3}{|c|}{ Flux density } \\
\hline & $\begin{array}{l}\text { Phiax } \\
\text { progr. }\end{array}$ & $\begin{array}{l}\text { Analit. } \\
\text { value }\end{array}$ & & $\begin{array}{l}\text { Phiax } \\
\text { progr. }\end{array}$ & $\begin{array}{l}\text { Analit } \\
\text { value }\end{array}$ & \\
\hline 1 & 3.8808 & 3.8823 & $.4 \%$ & 5.8381 & 5.8823 & $1 . \%$ \\
\hline 2 & 3.5859 & 3.5868 & $.3 \%$ & 5.4369 & 5.4346 & $.4 \%$ \\
\hline 3 & 2.7441 & 2.7452 & $.3 \%$ & 4.1628 & 4.1595 & $.6 \%$ \\
\hline 4 & 1.4853 & 1.4857 & $.1 \%$ & 2.2517 & 2.2511 & $.1 \%$ \\
\hline 5 & $.1 E-04$ & 0. & $.04 \%$ & $.4 E-05$ & & \\
\hline
\end{tabular}
gnetic sphere in a constant field $|5|$. We have choosen this example to test the method.

The sphere is discretised into 4 finite elements of second order (fig. 2). The accuracy of the solution on the boundary is better than $0.4 \%$ on the potential and $1 . \%$ on the normal flux density (fig. 3).

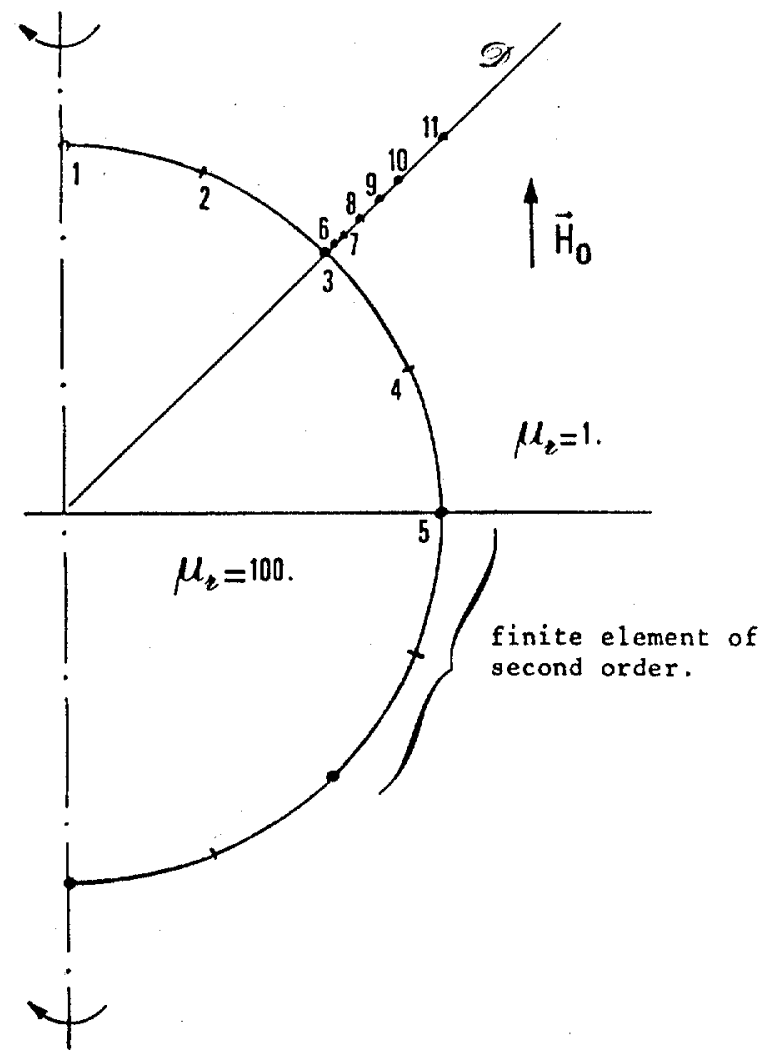

Fig. 2 : Finite element discretisation of the sphere.

Fig.3 : Solution on the boundary. 
The values of potential and flux density for 6 external points are also presented with comparison to analytical values (fig. 4). The points 6 and 7 are very near the boundary and the integration errors increase.

The same integrals give the angular factor " $C$ " $(|4|$; eq. (6)). So this coefficient becomes a "goodness factor" of the method and allows the definition of a forbidden area around the boundary where potential and magnetic field cannot be computed.

\begin{tabular}{|c|c|c|c|c|c|}
\hline Point & $\begin{array}{l}\text { Pote } \\
\text { Phiax } \\
\text { progr. }\end{array}$ & $\begin{array}{l}\text { ntial } \\
\text { Analit. } \\
\text { value }\end{array}$ & & & \\
\hline 3 & 2.7441 & 2.7452 & & & \\
\hline 6 & 2.5948 & 2.6114 & & & \\
\hline 7 & 2,4736 & 2.4402 & & & \\
\hline 8 & 2.1434 & 2.1447 & & & \\
\hline 9 & 1.8999 & 1.8998 & & & \\
\hline 10 & 1.6938 & 1.6946 & & & \\
\hline 11 & 1.3715 & 1.3726 & & & \\
\hline Point & $\begin{array}{l}H_{\rho} \\
\text { Phiax } \\
\text { progr. }\end{array}$ & $\begin{array}{l}\text { Analit. } \\
\text { value }\end{array}$ & $\begin{array}{l}\mathrm{H}_{z} \\
\text { Phiax } \\
\text { progr. }\end{array}$ & $\begin{array}{l}\text { Analit. } \\
\text { value }\end{array}$ & $\begin{array}{l}\text { Rel: error } \\
\text { on 'c' } \\
\text { see eq. (6) }\end{array}$ \\
\hline 3 & 2.9138 & 2.9118 & 0.9731 & 0.9706 & \multirow{7}{*}{$\begin{aligned} 7.5 \% & \times \\
11 . \% & \times \\
1 . \% & \end{aligned}$} \\
\hline 6 & -2.0787 & 2.7014 & -3.9932 & 0.9005 & \\
\hline 7 & 2.9622 & 2.4402 & 1.3445 & 0.8134 & \\
\hline 8 & 2.0131 & 2.0107 & 0.6744 & $0: 6702$ & \\
\hline 9 & 1.6701 & 1.6763 & 0.5522 & 0.5588 & \\
\hline 10 & 1.4101 & 1.4122 & 0.4691 & 0.4707 & \\
\hline 11 & 1.0284 & 1.0295 & 0.3427 & 0.3431 & \\
\hline
\end{tabular}

Fig.4: Potential and flux density on the straight line 9 .

$X$ points in the forbidden area.

CONCLUSTON

The method we developed and exposed is the complementary to the BIE programs already existing in $2 D$ and $3 D$. It solves a large set of problems at a low computing cost and needs a very short geometry description time. With PHI2D, PHI3D and now this PHIAX packages it is possible to solve with the BIE method all magnetostatic or electrostatic problems.

\section{REFERENCES}

11 ANCELLE B. : "Emploi de la méthode des équations intégrales de fontière et mise en oeuvre de la CAO dans les calculs des systèmes électromagnétiques" PH. D. Thesis - Grenoble 1979.

$2 \mid$ DURAND : "Electrostatique" - tome 1, Masson, Paris

3) ABRAMOWIT2 $M$. and STEGUN I.A. : "Handbook of mathematical functions". Dover Publication.

4) KRAHENBUHL L. and NICOLAS A. : "Efficient techniques for boundary equations method for potential problems". Compumag 83.

151 DURAND : "Magnétostatique" - Masson, Paris. 